\title{
Study on Etiology and Immediate Outcome of Adult Comatose Patients in Medical Ward
}

\section{Pijush Kanti Biswas, Arijit Sinha}

Section: Healthcare

Sci. Journal Impact

Factor: $6.1(2018)$

ICV: 90.90 (2018)

Associate Professors, Department of General Medicine, N.R.S Medical College, Kolkata 700014, India.

(c) (5) (8)

Copyright@IJCRR

\section{ABSTRACT}

Introduction: Adult comatose patients are challenging in General Medicine ward. Proper and prompt handling of such patients is important to get the best results. To reach etiological diagnosis early is important for the outcome.

Methods: It is an observational, analytical, prospective study among 300 adult non-traumatic comatose patients (GCS $\leq 10$ ) admitted in the Medical ward. Cases were evaluated with details history, clinical examinations, investigations. The etiological and immediate outcome was assessed.

Results: In our study, most common causes were stroke (48.99\%) followed by metabolic derangement $(28.98 \%)$, infection $(14.3 \%)$, poisoning $(5.66 \%)$ and malignancy $(2 \%)$. Among death patients, stroke is in the top $(71.1 \%)$ then metabolic causes (13.32\%), infection (7.4\%), poisoning (5.92\%), malignancy (2.22\%). Among 300 patients 32\% had one or more co-morbid illness.

Conclusion: Stroke is the most common cause of non-traumatic coma but metabolic and infective causes are equally important in a tertiary care hospital.

Key Words: GCS (Glasgow Coma Scale), NTC (Non-Traumatic Coma), Adult comatose patients

\section{INTRODUCTION}

Comatose patients are challenging to a doctor. About 5 to $9 \%$ of all patients attending emergency are with disorders of consciousness of non-traumatic origin and are associated with high (25-48\%) mortality. ${ }^{1,2}$ Etiology and clinical presentations are important to predict the outcome. Most of the studies with non-traumatic coma patients used GCS $\leq 10$ as a cut-off score. ${ }^{3,4}$ Coma may be without focal neurological signs (metabolic and toxic encephalopathies), with prominent focal signs (stroke) and meningitis syndromes, acute encephalitic syndromes. Drug ingestion, cerebral haemorrhage, cardiac arrest, epilepsy, basilar artery occlusion are common causes of sudden coma. Secondary to pre-existing medical or neurological illness, coma can appear sub-acutely due to brain oedema or infarction. ${ }^{5}$ GCS score provide the best indication to predict mortality in non-traumatic coma cases. ${ }^{6}$ Metabolic causes of the coma have better outcome. ${ }^{7}$ GCS score, onset, cause, pre-existing comorbidities are an important factor for outcome in nontraumatic coma cases.

\section{MATERIALS AND METHODS}

It is an observational, analytical, prospective study among 300 adult comatose patients admitted at the medical ward in a single centre tertiary care hospital, N.R.S Medical College, Kolkata within a period of one year (Nov 2018 to Oct 2019). Comatose patients with GCS $\leq 10$ and age $>20$ years were included in this study. We aimed to study aetiology of adult comatose patients and immediate outcome concerning aetiology, within four weeks of presentation. After a proper explanation about the study, assent from the nearest relative was taken. Details history, clinical examination and relevant investigations were done. Lab investigation included - capillary blood glucose, serum sodium, serum potassium, complete hemogram, urea, creatinine, liver function test, arterial blood gas analysis, hepatitis B, C, A, E, HIV screening, blood ammonia, ANA profile, coagulation profile, CSF analysis, urine ketone bodies, serum osmolality, ECG, CT scan brain, chest X-ray PA view, MRI brain, CT scan chest/abdomen, EEG according to need. Patients were followed up at the out-patient department (4 weeks for our study). Results were analyzed statistically.

\section{Corresponding Author:}

Dr. Arijit Sinha, Associate Professors, Department of General Medicine, N.R.S Medical College, Kolkata 700014, India. Mobile: +91 9434016561; Email: drarijitsinha66@gmail.com

ISSN: 2231-2196 (Print)

Received: 23.07 .2020
ISSN: $0975-5241$ (Online)

Revised: 12.09 .2020
Accepted: 14.10 .2020
Published: 14.12 .2020 
Ethical clearance was taken from Institutional Ethics Committee (IEC- No/NMC/7656, dt- 17/12/2018).

\section{RESULTS}

Among 300 adult comatose patients (GCS $\leq 10)$, Male: Female ratio was $1: 1$. Hindu was maximum in number $(70 \%, n=$ $210), 46 \%(\mathrm{n}=138)$ was urban population and $62 \%(\mathrm{n}=186)$ was above poverty level (APL). Average hospital stay, GCS was 7.1 and 7 respectively. Most of the patients were in the age (years) group of 51-60 $(22 \%, \mathrm{n}=66), 61-70(18 \%, \mathrm{n}=54)$, $41-50(16 \%, n=48)$ [Table 1]. Median age of patient was 54.5 years. Death rate was $45 \%(\mathrm{n}=135)$. Co morbidity was present in $32 \%(\mathrm{n}=96)$. Among 300 patients $14.66 \%(\mathrm{n}=44)$ were smoker, 9.33\% $(\mathrm{n}=28)$ were alcoholic, $15 \%(\mathrm{n}=45)$ were diabetic, $29.66 \%(\mathrm{n}=89)$ were hypertensive, $4 \%(\mathrm{n}=12)$ were of cardiac disease, $3.66 \%(\mathrm{n}=11)$ were with kidney disease, $3 \%(n=9)$ were associated with malignant disease, $3 \%$ $(\mathrm{n}=9)$ were chronic hepatitis, $1.33 \%(\mathrm{n}=4)$ connective tissue disorder (SLE). $1.33 \%(\mathrm{n}=4)$ were HIV [Table 2]. Among comatose patients $30 \%(\mathrm{n}=90)$ was with GCS $3-6,70 \%$ was GCS 7-10. Mortality in GCS 3-6 score was $70 \%$ ( $n=63$ out of 90 patients) and in 7-10 score was $34.28 \%$ ( $\mathrm{n}=72$ out of 210 patients) [Table 3]. Male female ratio among dead patients was 1.17:1. Maximum death occurred in 61-70 age group (25.92\%of total death) but age group wise mortality was more in 61-79 and 81-90 group (66.6\%). Commonest etiology was stroke $(48.99 \%)$. Intracerebral / cerebellar hemorrhage (ICH) was $32.66 \%$, infarction $12.37 \%$, sub arachnoid hemorrhage $4 \%$. After stroke metabolic derangements (hepatic encephalopathy, diabetic keto acidosis/ hyperosmolar coma, hyponatremia, hypoglycemia, uremia) takes the second place $(28.98 \%)$ in etiology. Next comes infective causes (14.3\%), which includes -septicemia (4.33\%), pneumonia (3.37\%), scrub typhus encephalitis. Among death patients, stroke is in the top (71.1\%) then metabolic (13.32\%), infection $(7.4 \%)$, poisoning $(5.92 \%)$, malignancy $(2.22 \%)$. Individual etiology wise mortality rate was- $\mathrm{ICH} 77.55 \%$, uremia $75 \%$, poisoning $50 \%$, sepsis $46.15 \%$ [Table 4,5 ].

\section{DISCUSSION}

After analysis of aetiology in our study, we found that stroke (ICH, infarction, SAH) was the predominant cause (48.99\%) of non-traumatic adult comatose patients with GCS $<=10$ in the medical ward. Among stroke patients, ICH, infarction, SAH was at $32.66 \%, 12.33 \%, 4 \%$ respectively. Esquevin et al. found stroke as a major cause $(54 \%)$ of NTC and Greev et al. found it $49 \%$. We found $28.98 \%$ as the metabolic cause, Esquevin et al. mentioned it 31\%. Mwanja $\mathrm{K}$ et al. found $20 \%$ mortality among comatose DKA patients. ${ }^{3,8,9}$ Infectious causes of coma (including Sepsis, TBM, Pyogenic menin- gitis, Dengue, Malaria, Scrub typhus) was found in 14.3\% cases. Home et al found $6 \%$ of cases with CNS infection in their study. ${ }^{10}$ Poisoning is another important cause of coma in the Medical ward. In our study, 5.66\% cases admitted with a history of snakebite, organo-phosphorous poisoning, paraquat poisoning, sedative overdose. Thacker et al. found $57.5 \%$ intracranial, $26 \%$ metabolic, $5 \%$ drug/poison ingestion as a cause of non-traumatic coma. ${ }^{11}$ Whereas Plum and Posner found $45.2 \%, 21.4 \%, 29.5 \%$ as intracranial, metabolic, drugs/poisoning aetiology in their study. ${ }^{12}$ GCS on admission has a direct correlation with the outcome. Dhamija et al found $84 \%$ mortality in 3 to 4 GCS score. ${ }^{13}$ In our study $70 \%$ mortality found in 3 to 6 GCS score group. Our $45 \%$ patients (GCS $<=10$ ) patients expired and most death occurs in 61-70, 81-90 age group, with Stroke77.55\% (ICH 56.29\%). Esquevin et al. studied with 65 patients with GCS $<=10$ and mortality was $52 \%$ after 3 months. Mortality due to Stroke was observed $83 \%$ in Esquevin et al study, 69\% in Owolabi et al. study. ${ }^{3,14}$ Hypertension (29.66\%), Diabetes (15\%) were major comorbidities in our study( Table 4,5). That was noticed in different studies in Stroke related diseases. ${ }^{15}$ However, this study has a limitation that patients with GCS $<10$ died within a few hours of admission and some patients did not follow up within four of discharge.

\section{CONCLUSION}

Though Stroke is the predominant cause of adult comatose patients $(\mathrm{GCS}<=10)$, metabolic and infective causes are increasing day by day. So quick identification of aetiology is important for prognostic value. Poor GCS has a poor outcome. Counselling of patient party is equally important on initial evaluation.

\section{ACKNOWLEDGEMENT}

We acknowledge the help of our postgraduate students. We also acknowledge the immense help received from the scholars whose articles are cited and included in references for this manuscript. We are also grateful to authors/editors/publishers of all those articles journals and books from where the literature of the article has been reviewed and discussed.

\section{Conflict of interest: Nil}

\section{Source of funding: Nil}

Ethical clearance: Taken from Institutions Ethical Committee (No/NMC/7656, dt-17/12/2018)

\section{Abbreviations}

GCS (Glasgow Coma Scale), NTC (Non-Traumatic Coma), Adult comatose patients, ICH (Intracerebral, Cerebellar Hemorrhage), SAH (Sub Arachnoid Hemorrhage), AES 
(Acute Encephalitis Syndrome).

\section{REFERENCES}

1. Kanich W, Brady WJ, Huff JS, Perron AD, Holstege C, Lindbeck G, et al. Altered mental status: evaluation and aetiology in the ED. Am J Emerg Med 2002;20(7):613-17.

2. Weiss N, Regard L, Vidal C, Luque Y, Taldir G, Vallet H, et al. Causes of coma and their evaluation in the medical intensive care unit. J Neurol 2012;259(7):1474-77.

3. Esquevin A, Raoult H, Ferre JC, Ronziere T, Stamm A, Perennes $\mathrm{M}$, et al. Systemic combined non-contrast CT-CT angiography in the management of unexplained non-traumatic coma. Am J Emerg Med 2013;31(3):494-98.

4. Forsberg S, Hojer J, Enander C, Ludwigs U. Coma and impaired consciousness in the emergency room: Characteristics of poisoning versus other causes. Emerg Med J 2009;26(2):100-2.

5. Joseph SA, Ropper AH, Hauser SL. Coma, In Jameson, Fauci, Kasper, Hauser, Longo, Loscalzo, editors, Harrison's Principles Of Internal Medicine, 20th edition, vol 2, Mc Graw Hill Education, 2018;2068-74.

6. Sacco RL, VanGool R, Mohr JP, Hauser WA. Non-traumatic coma: GCS and coma aetiology as predictors of 2-week outcome, Arch Neurol 1990;47(11):1181-84.

7. Edlow JA, Rabinstein A, Traub SJ, Wijdicks EFM. Diagnosis of reversible causes of coma. Lancet 2014;384(9959):2064-76.

8. Mwanja K, Brown K, Owen N, Soka N. Comatose and noncomatose adult diabetic ketoacidosis patients at the University
Teaching Hospital, Zambia, clinical profile, risk factors and mortality outcome. Ind J Endocrinol Metab 2016;20(2):199-205.

9. Greer DM, Yang J, Scripko PD, Sims JR, Cash S, Kilbride R, et al. Clinical examination for outcome prediction in a nontraumatic coma. Crit Care Med 2012;40(4):1150-6.

10. Hamel MB, Goldman L, Teno J, Lynn J, Davis RB, Jr Harell FE, et al. Identification of comatose patients at high risk for death or severe disability. SUPPORT investigators. Understand prognoses and preferences for outcomes and risks of treatments. JAMA 1995;273(23):1842-48.

11. Thacker AK, Singh BN, Sarkari NB, Mishra RK. Non-traumatic coma- profile and prognosis. JAPI 1997;45(4):267-70.

12. Posner JB, Saper CB, Schiff ND, Classen J, Pathophysiology of signs and symptoms of coma. In Posner JB, Saper CB, Schiff ND, Classen J, editors, Plum and Posner's, Diagnosis and treatment of stupor and coma, 5th edition, Oxford University Press, 2019;1-42.

13. Dhamija RM, Dewan N, Venkataraman S, Rana PVS, Mohapatro AK, Prognosis in a non-traumatic coma. JAPI 1991;39:56.

14. Owolabi LF, Mohammed AD, Dalhat MM, Ibrahim A, Aliyu S, Owolabi DS. Factors associated with death and predictors of 1month mortality in a nontraumatic coma in a tertiary hospital in Northwestern Nigeria. Indian J Crit Care Med. 2013;17(4):21923.

15. Magwood GS, White BM, Ellis C. Stroke related disease comorbidity and secondary stroke prevention practices among young stroke survivors. J Neurosci Nurs 2019;49(5):296-301.

Table 1: Age group distribution and outcome (no. of cases, death, recovered patients, age group wise death), GCS $<=10$

\begin{tabular}{lcccc}
$\begin{array}{l}\text { Age group } \\
\text { (Years) }\end{array}$ & $\begin{array}{c}\text { No of cases with } \% \\
(\mathbf{n}=300)\end{array}$ & $\begin{array}{c}\text { No of deaths with \% } \\
(\mathbf{n}=135)\end{array}$ & $\begin{array}{c}\text { No of recovered cases } \\
\text { with \%(n=165) }\end{array}$ & $\begin{array}{c}\text { Death \% in individual } \\
\text { age group }\end{array}$ \\
\hline $21-30$ & $41(13.66 \%)$ & $10(7.4 \%)$ & $31(18.78 \%)$ & $24.39 \%$ \\
$31-40$ & $42(14 \%)$ & $12(8.88 \%)$ & $30(18.81 \%)$ & $28.57 \%$ \\
$41-50$ & $48(16 \%)$ & $16(11.85)$ & $32(19.39 \%)$ & $33.33 \%$ \\
$51-60$ & $66(22 \%)$ & $35(25.95)$ & $31(18.78 \%)$ & $53.03 \%$ \\
$61-70$ & $54(18 \%)$ & $36(26.66 \%)$ & $18(10.90 \%)$ & $66.66 \%$ \\
$71-80$ & $43(14.33 \%)$ & $22(16.29 \%)$ & $21(12.72 \%)$ & $51.16 \%$ \\
$81-90$ & $6(2 \%)$ & $4(2.96 \%)$ & $2(1.21 \%)$ & $66.66 \%$ \\
\hline
\end{tabular}

Table 2: Etiology, risk factor, co morbidity $(>=1)$ and outcome among death cases, GCS $<=10$

\begin{tabular}{lccc} 
Etiology & $\begin{array}{c}\text { Total no of death, } \\
\mathrm{n}=135\end{array}$ & With risk factor, co morbidity, 96 & Without risk factor co morbidity, 39 \\
Stroke & $96(71.1 \%)$ & $67(69.79 \%)$ & $29(74.35 \%)$ \\
Metabolic & $18(13.32 \%)$ & $18(18.75 \%)$ & -- \\
Infective & $10(7.4 \%)$ & $6(6.25 \%)$ & $4(10.25 \%)$ \\
Poisoning, Snake bite & $8(5.92 \%)$ & $2(2.08 \%)$ & $6(15.38 \%)$ \\
Malignancy & $3(2.22 \%)$ & $3(3.12 \%)$ & -- \\
\hline
\end{tabular}

p-value $=$ death with risk factor, co-morbidity and death without risk factor, co-morbidity among stroke and other causes of death $<0.59$ (insignificant) 
Table 3: GCS and outcome, GCS <=10

\begin{tabular}{lccc} 
GCS & Total no, $\mathbf{n}=300$ & Death, 135 & Survived, 165 \\
3-6 & $90(30 \%)$ & $76(56.29 \%)$ & $14(8.84 \%)$ \\
$7-10$ & $210(70 \%)$ & $59(43.70 \%)$ & $151(91.95 \%)$ \\
\hline
\end{tabular}

Table 4: Etiology distribution and outcome, GCS $<=10$

\begin{tabular}{|c|c|c|c|}
\hline Etiology of coma & $\begin{array}{c}\text { No of cases with \% } \\
(\mathbf{n}=300)\end{array}$ & $\begin{array}{c}\text { No of deaths with \% } \\
(n=135)\end{array}$ & Death \% in individual etiology \\
\hline Stroke (ICH) & $98(32.66 \%)$ & $76(56.29 \%)$ & $77 \cdot 55 \%$ \\
\hline Stroke (Infarct) & $37(12.33 \%)$ & $16(11.85 \%)$ & $43.24 \%$ \\
\hline Stroke (SAH) & $12(4 \%)$ & $4(2.96 \%)$ & $33 \cdot 33 \%$ \\
\hline Snakebite & $5(1.66 \%)$ & $2(1.48 \%)$ & $40 \%$ \\
\hline Sedative, PQ, OP & $12(4 \%)$ & $6(4.44 \%)$ & $50 \%$ \\
\hline Malignancy & $6(2 \%)$ & $3(2.22 \%)$ & $50 \%$ \\
\hline Pneumonia & $10(3.33 \%)$ & $2(1.48 \%)$ & $20 \%$ \\
\hline Sepsis & $13(4.33 \%)$ & $6(4 \cdot 44 \%)$ & $46.15 \%$ \\
\hline ТВ M & $8(2.66 \%)$ & $1(0.74 \%)$ & $12.5 \%$ \\
\hline Pyogenic M & $2(0.66 \%)$ & $1(0.74 \%)$ & $50 \%$ \\
\hline Scrub typhus & $2(0.66 \%)$ & -- & -- \\
\hline Dengue & $2(0.66 \%)$ & -- & -- \\
\hline Malaria & $6(2 \%)$ & -- & -- \\
\hline Hepatic & $12(4 \%)$ & $6(4 \cdot 44 \%)$ & $50 \%$ \\
\hline DKA & $12(4 \%)$ & $3(2.22 \%)$ & $25 \%$ \\
\hline Hypoglycemia & $16(5 \cdot 33 \%)$ & -- & -- \\
\hline Hyperosmolar & $8(2.66 \%)$ & $3(2.22)$ & $37 \cdot 5 \%$ \\
\hline Uremia & $8(2.66 \%)$ & $6(4 \cdot 44 \%)$ & $75 \%$ \\
\hline Hyponatremia & $29(9.66 \%)$ & -- & -- \\
\hline Myxedema & $1(0.33 \%)$ & -- & -- \\
\hline Adrenal insufficiency & $1(0.33 \%)$ & -- & -- \\
\hline
\end{tabular}

ICH- intra cerebral/cerebellar hemorrhage, SAH- sub arachnoid hemorrhage, PQ- paraquat, OP- organo-phosphorous, Mmeningitis, TB- tubercular, DKA diabetic keto acidosis

Table 5: Etiology and outcome significance, GCS <=10

\begin{tabular}{lccc} 
Etiology & Total no, $\mathbf{n = 3 0 0}$ & Death, 135 & Survived, 165 \\
Stroke & $147(48.99 \%)$ & $96(71.1 \%)$ & $51(30.90 \%)$ \\
Metabolic & $87(28.98 \%)$ & $18(13.32)$ & $69(41.81 \%)$ \\
Infective & $43(14.3 \%)$ & $10(7.4 \%)$ & $33(20 \%)$ \\
Poisoning, Snake bite & $17(5.66 \%)$ & $8(5.92 \%)$ & $9(5.45 \%)$ \\
Malignancy & $6(2 \%)$ & $3(2.22 \%)$ & $3(1.81 \%)$ \\
\hline
\end{tabular}

